\title{
Telomere tracking from birth to adulthood and residential traffic exposure
}

\author{
Esmée M. Bijnens ${ }^{1,2}$, Maurice P. Zeegers ${ }^{2,3}$, Catherine Derom, ${ }^{4,5}$, Dries S. Martens ${ }^{1}$, Marij Gielen², Geja J. Hageman \\ Michelle Plusquin ${ }^{1}$, Evert Thiery ${ }^{7}$, Robert Vlietinck ${ }^{5}$ and Tim S. Nawrot ${ }^{1,8^{*}}$
}

\begin{abstract}
Background: Telomere attrition is extremely rapid during the first years of life, while lifestyle during adulthood exerts a minor impact. This suggests that early life is an important period in the determination of telomere length. We investigated the importance of the early-life environment on both telomere tracking and adult telomere length.

Methods: Among 184 twins of the East Flanders Prospective Twin Survey, telomere length in placental tissue and in buccal cells in young adulthood was measured. Residential addresses at birth and in young adulthood were geocoded and residential traffic and greenness exposure was determined.

Results: We investigated individual telomere tracking from birth over a 20 year period (mean age (SD), 22.6 (3.1) years) in association with residential exposure to traffic and greenness. Telomere length in placental tissue and in buccal cells in young adulthood correlated positively $(r=0.31, P<0.0001)$. Persons with higher placental telomere length at birth were more likely to have a stronger downward shift in telomere ranking over life $(P<0.0001)$.

Maternal residential traffic exposure correlated inversely with telomere length at birth. Independent of birth placental telomere length, telomere ranking between birth and young adulthood was negatively and significantly associated with residential traffic exposure at the birth address, while traffic exposure at the residential address at adult age was not associated with telomere length.
\end{abstract}

Conclusions: Longitudinal evidence of telomere length tracking from birth to adulthood shows inverse associations of residential traffic exposure in association with telomere length at birth as well as accelerated telomere shortening in the first two decades of life.

Keywords: Telomere length, Traffic, Tracking

\section{Background}

Telomeres are located at the end of chromosomes and protect these regions from degradation [1]. Most human somatic tissues are not able to maintain telomere length, with telomeres shortening during cell division and resulting in telomere attrition with cellular age [2]. Eventually, telomeres reach a critical length, leading to loss of protection and chromosomal instability [3]. Short telomeres have been implicated in the pathology of several age-related diseases, including cardiovascular disease [4], diabetes mellitus [5], and cancer [6, 7]. Moreover, an association between telomere

\footnotetext{
* Correspondence: tim.nawrot@uhasselt.be

${ }^{1}$ Centre for Environmental Sciences, Hasselt University, Agoralaan Building D,

3590 Diepenbeek, Belgium

${ }^{8}$ Department of Public Health, Leuven University (KU Leuven), Leuven,

Belgium

Full list of author information is available at the end of the article
}

length and mortality has been observed in studies of elderly twins, showing that the twin with the shortest telomere length has a greater risk of death during follow-up compared to the co-twin with the longest telomeres $[8,9]$. These results indicate that telomere length functions as a measure of biological aging $[10,11]$.

The decline of telomere length with age has been observed in longitudinal studies starting from early adult life until advanced age [12-14]. However, cross-sectional studies comparing individuals with a wide age range, from neonates to the elderly, observed that the rate of telomere attrition varied at different ages $[15,16]$. Further, in more than 500 individuals, aged from 0 to 90 years, telomere loss was more pronounced in the first year and continued thereafter at a slower rate [16]. In addition, a longitudinal study measuring telomere length in samples 
donated 12 years apart by 1156 participants observed that, in adults, telomere length ranking does not change much over time [17]. These results suggest that most of the inter-individual variation in telomere length among adults is established early in life and that lifestyle during adulthood exerts only a minor impact on telomere ranking [17]. Thus, early life is an important period in the determination of telomere length and could have a lasting effect on telomere length throughout the life course [18].

Telomere length has been associated with exposure to different types of air pollution [11, 19-21]. Shorter leukocyte telomere length was observed in traffic officers compared to office workers [20] and long-term exposure to airborne particles, especially those related to traffic, is associated with faster telomere attrition in 70-year-olds [19].

Compared with term-born singletons, twins are more susceptible to prenatal exposure of particulate air pollution [22]. In addition, we observed in previous research that maternal residential proximity to traffic and lower residential surrounding greenness is associated with shorter placental telomere length at birth in twins [23]. Currently, there is a gap in the understanding of the importance of the early-life environment on both telomere tracking and adult life telomere length. Herein, we measured telomere length at birth in placental tissue and in young adulthood in buccal cells to determine if early-life exposure to traffic has long-term consequences on telomere length. Further, we studied the effects of traffic exposure early in life on telomere tracking over the first two decades of life.

\section{Methods}

\section{Subjects}

The East Flanders Prospective Twin Survey, a populationbased register of multiple births in the province of East Flanders (Belgium), commenced enrollment of twins at birth in 1964 [24]. The twin-population in our study was based on a previous twin study by Loos et al. [25]. Young adult twins aged 18-34 years (803 pairs) were randomly contacted through an envelope system. Eventually, 424 pairs (overall response of 52.8\%) agreed to participate [25]. The present study sample consisted of 233 twins of Caucasian origin (99\% naturally conceived), born between 1969 and 1982, who participated in a prenatal programming study and had both placental telomere length and buccal swabs at adulthood available. We excluded 49 participants from our analysis (1) because DNA quality or concentration was insufficient $(n=21)$ or because triplicate measurements of telomere length were too variable (difference in quantification cycle more than 0.50) $(\mathrm{n}=7)$, (2) because residential address was missing $(n=10)$, or (3) because information on smoking status during pregnancy was not provided in the questionnaire $(\mathrm{n}=11)$. The number of twins included in our analysis was 184. The dropout rate of the present study is described in the flowchart (Fig. 1).

\section{Telomere length measurements in placental tissue}

All placental biopsies were taken from the maternal side of the placenta, $2 \mathrm{~cm}$ from the umbilical cord insertion site, free of maternal decidua and stored at $-20{ }^{\circ} \mathrm{C}$. Prior to DNA isolation the placental tissue was washed with phosphate-buffered saline to remove possible traces of maternal blood. DNA was isolated from placental tissue using the QIAamp DNeasy blood and tissue kit (Qiagen, Venlo, The Netherlands), following the manufacturer's instructions for animal tissues. Quality and concentration of the isolated placental DNA were assessed using the Nanodrop 1000 spectrophotometer (Isogen Life Science, Belgium). Twin pairs were excluded from the analyses when DNA samples had a low yield or to absorption ratios for A260/A280 that were outside the range of 1.8 to 2.0. The methods for telomere length measurement in placental tissue have been previously described [23, 26]. In brief, telomere length was determined using a monochrome multiplex quantitative PCR (q-PCR) method [27]. For multiplex q-PCR, telomere primer pairs telg (at $900 \mathrm{~nm}$; ACACTAAGGTTTGGGTTTGGGTTTG GGTTTGGGTTAGTGT) and telc (at $900 \mathrm{~nm}$; TGTTAGG TATCCCТATCCCТATCCCTATCCCТATCCCTAACA) were combined with the beta-globin primer pairs hbgu (at $500 \mathrm{mM}$; CGGCGGCGGGCGGCGCGGGCTGGGCGGcttcatccacgttca ccttg) and hbgd (at $500 \mathrm{mM}$; GCCCGGCCCGCCGCGCCC GTCCCGCCGgaggagaagtctgccgtt). Reference genomic DNA (Hela 229 cell line, telomere length of $14.5 \mathrm{kbp}$ ) was used to generate two standard curves for each PCR plate, one for the telomere signal and one for the single copy gene signal to determine primer efficiency. Samples were assayed in triplicate and the average was used. Based on the reference samples, the coefficient of variation was $2.5 \%$ for within plate measurements and $4.9 \%$ for measurements between plates. The inter-assay coefficient of variation was $13.03 \%$. We observed no correlation between the coefficient of variation with mean placental telomere length of the triplicates $(\mathrm{r}=0.06 ; P=0.40)$.

\section{Telomere length measurements in buccal cells}

Mouth swabs were taken and DNA was extracted with the QIAamp DNA micro kit (Qiagen, Venlo, The Netherlands). DNA purity and concentration was assessed using the Nanodrop 1000 spectrophotometer (Isogen Life Science, Belgium). Due to a low DNA yield or to absorption ratios for A260/A280 that were outside the range of 1.8 to 2.0 for buccal DNA, 21 individuals were excluded from the analyses. Relative telomere length was measured in buccal swabs using an adapted quantitative real-time PCR method [27]. Relative telomere length is based on the ratio of telomere sequence repeats to a single copy nuclear control 


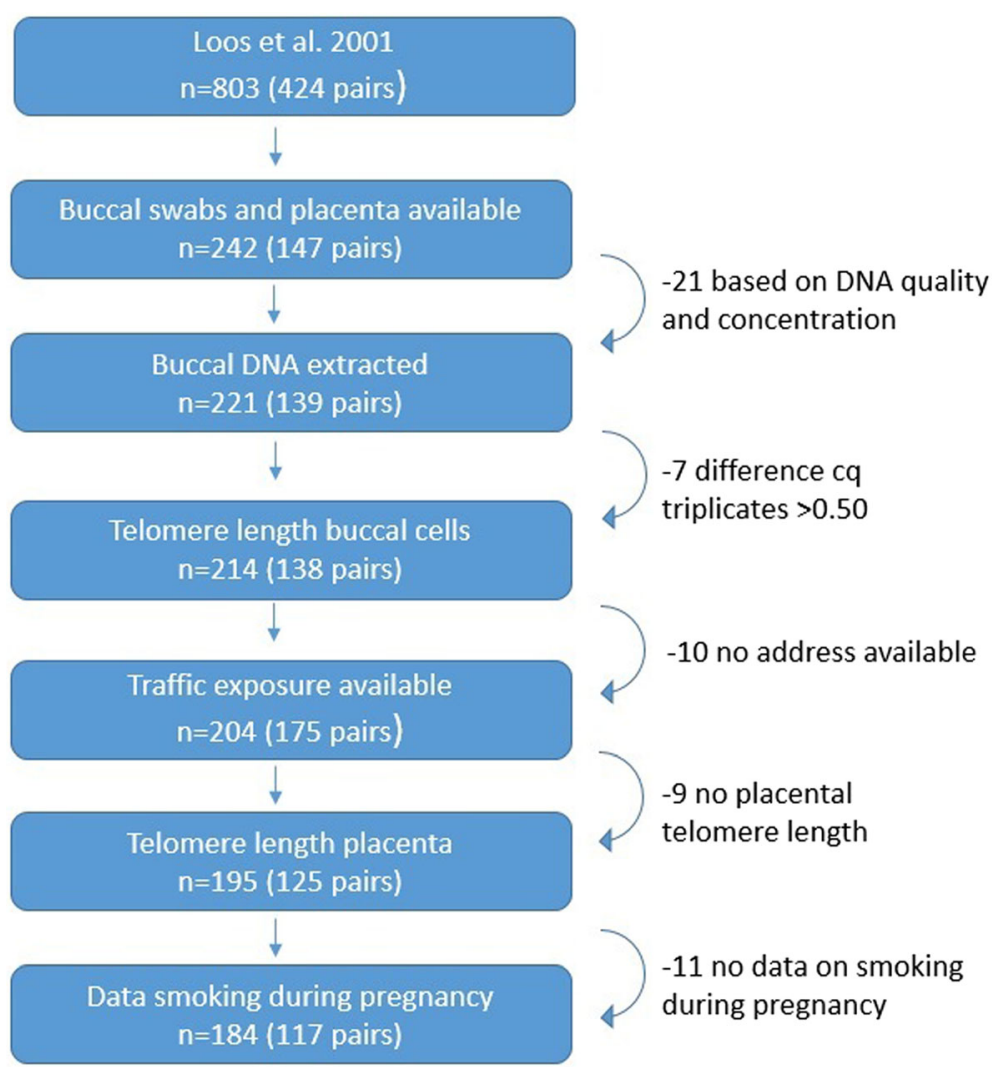

Fig. 1 The present study sample consisted of 233 twins of Caucasian origin (99\% naturally conceived), born between 1969 and 1982, who participated in a prenatal programming study and had both placental telomere length and buccal swabs at adulthood available. We excluded 49 participants from our analysis (1) because DNA quality or concentration was insufficient $(n=21)$ or because triplicate measurements of telomere length were too variable (difference in quantification cycle more than 0.50$)(n=7)$, (2) because residential address was missing $(n=10)$, or (3) because information on smoking status during pregnancy was not filled out in the questionnaire $(n=11)$. The number of twins included in our analysis was 184

gene, 36B4 (acidic ribosomal phosphoprotein P0) [27]. Extracted genomic DNA was diluted, resulting in a final input of $5 \mathrm{ng}$. The telomere PCR reaction mixture contained $1 \mathrm{X}$ QuantiTect SYBR ${ }^{\circ}$ Green (Qiagen, Venlo, The Netherlands) Mastermix, $300 \mathrm{nM}$ primer telg (ACACTAAGGTTTGGG TTTGGGTTTGGGTTTGGGTTAGTGT), 900 nM primer telc (TGTTAGGTATCCCTATCCCTATCCCTATCC CTATCCCTAACA), and $2.5 \mathrm{mM}$ DTT. The single copy gene PCR reaction mixture contained 1X QuantiTect $\mathrm{SYBR}^{\circledR}$ Green (Qiagen, Venlo, The Netherlands) Mastermix, $300 \mathrm{nM}$ forward (CAGCAAGTGGGAAGGTGTAATCC), and $500 \mathrm{nM}$ reverse primer (CCCATTCTATCATCAACG GGTACAA).

Each PCR reaction was performed in triplicate and three non-template controls as well as six inter-run calibrators were included on each 384-well plate. All samples were analyzed using a 7900HT Fast Real-Time PCR system (Life Technologies). Telomere PCR conditions were one cycle at $95{ }^{\circ} \mathrm{C}$ for $10 \mathrm{~min}$ followed by two cycles of $15 \mathrm{sec}$ at $94{ }^{\circ} \mathrm{C}$ and $2 \mathrm{~min}$ at $49{ }^{\circ} \mathrm{C}$, and 30 cycles of $15 \mathrm{sec}$ at $94{ }^{\circ} \mathrm{C}, 20 \mathrm{sec}$ at $62{ }^{\circ} \mathrm{C}$, and $1 \mathrm{~min} 40 \mathrm{sec}$ at
$74{ }^{\circ} \mathrm{C}$. Single copy gene PCR conditions were one cycle at $95{ }^{\circ} \mathrm{C}$ for $10 \mathrm{~min}$ followed by 40 cycles of $15 \mathrm{sec}$ at $95{ }^{\circ} \mathrm{C}$ and $1 \mathrm{~min} 10 \mathrm{sec}$ at $58{ }^{\circ} \mathrm{C}$.

After thermal cycling, raw data were collected and processed. The relative average telomere length was calculated as the ratio of the cycle threshold value of telomere sequence repeat to single copy gene $(\mathrm{T} / \mathrm{S})$ in the study subjects compared with that of the averaged $\mathrm{T} / \mathrm{S}$ value for the study population using the qBase software (Biogazelle, Zwijnaarde, Belgium). This program uses modified software from the classic comparative cycle threshold method and uses inter-run calibration algorithms to correct for run-to-run differences [28]. All samples were analyzed in triplicate and included in the study when the difference in quantification cycle value was less than 0.50 . The coefficients of variation within triplicates of the telomere and single copy gene assay were $0.48 \%$ and $0.31 \%$, respectively. The inter-assay coefficient of variation was $7.38 \%$. We observed no correlation between the coefficient of variation with the mean buccal telomere length of the triplicates $(\mathrm{r}=0.10 ; P=0.17)$. 


\section{Data collection}

Data recorded by the obstetrician at birth included gestational age, birth weight, sex of the twins, and parental ages. Gestational age was based on the last menstruation and was calculated as the number of completed weeks of pregnancy. Zygosity was determined at birth by sequential analysis based on sex, choriontype, blood group determined on umbilical cord blood, placental alkaline phosphatase and, since 1982, DNA fingerprints [29]. After DNA-fingerprinting, a zygosity probability of $99.9 \%$ was reached.

At a later stage, the parents of the twins filled out questionnaires. In this way, maternal smoking during pregnancy and parental educations was collected retrospectively. Educational level as a proxy of socioeconomic status was categorized into three groups according to the Belgian education system, namely as no education or primary school, lower secondary education, and higher secondary education and tertiary education. The twins completed questionnaires to obtain information on smoking status.

Biometric and laboratory measurements of adult twins were obtained at the research center during a 2-h morning session. Body mass index was calculated as body mass (in $\mathrm{kg}$ ) divided by squared height (in $\mathrm{m}$ ). Total cortisol was determined in 24-h urine using the ADVIA Centaur Cortisol assay. In fasting blood samples, gamma-glutamyl transferase was measured on an Olympus AU600 AutoAnalyzer (Kyoto, Japan). We use gamma-glutamyl transferase as a marker of alcohol intake [30]. Cortisol, which is synthesized from cholesterol, is a biochemical marker of chronic stress [31].

\section{Traffic exposure}

Residential addresses of the mothers at time of birth of the twins and the residential addresses of the twins at time of the measurement were geocoded. Residential distances to the nearest major road was determined using Geographic Information System functions. Major roads were defined by two types of roads, namely freeways and national roads. All Geographic Information System analyses were performed using ArcGIS 10 software.

\section{Statistical analysis}

For data management and statistical analyses, we used SAS software, version 9.4 (SAS Institute, Cary, NC). All reported $P$ values are two-sided and were considered statistically significant when $P<0.05$. The distribution of all variables was inspected and the measure of distance from residence to major road was log-transformed because this parameter had a skewed distribution and also because traffic-related pollutants decay exponentially with increasing distance from roads $[32,33]$.

Because telomere measurements were measured in different tissues at baseline (placenta) and follow-up (buccal cells), we used a ranking approach to study telomere tracking over a median follow-up of 22.6 years (range, 18.0-29.8). First, we ranked relative telomere length from long to short at birth (placental) and at young adulthood (buccal). The newborn with the longest telomere was coded as 1 and the newborn with the shortest was coded as 184 , the same procedure was applied for adult telomere length. Subsequently, we calculated the difference between the telomere rank for each individual by subtracting the rank at adulthood from the rank at birth. Because this difference in ranking depends also on the number of subjects in the population, we converted this to obtain a value with a maximum of 100 to facilitate interpretation. A positive value indicates an increase in ranking and a negative value a decrease in ranking from birth to young adulthood as a relative change between telomere length at birth and young adulthood compared with other individuals of the study population.

The difference in telomere ranking $(\Delta \mathrm{R})$ between birth and adulthood was calculated as follows:

$$
\Delta R=\frac{\left(R_{1}-R_{2}\right)}{\left(\frac{n-1}{100}\right)}
$$

Where $\mathrm{n}$ is the number of subjects in study population, $\mathrm{R} 1$ is the rank (from 1 to $\mathrm{n}$ ) based on telomere length at birth, and R2 is the rank (from 1 to $\mathrm{n}$ ) based on telomere length in adulthood.

Mixed modeling was performed to investigate buccal telomere length in young adulthood and telomere tracking in association with covariates. To differentiate between earlylife and adulthood exposure to traffic and greenness, we performed stratified analysis for twins who were living at the same address their whole life (non-movers, $\mathrm{n}=62$ ) and twins who were living at a different address than their birth address at the time of sample collection (movers, $\mathrm{n}=122$ ) [34].

The twins were analyzed as individuals in a multilevel regression analysis to account for relatedness between twin members by adding a random intercept to the model. The variance-covariance structure was allowed to differ between the three zygosity and chorionicity groups, including dizygotic dichorionic, monozygotic dichorionic, and monozygotic monochorionic. Mixed modeling was performed adjusted for covariates selected a priori, namely newborn sex, birth weight, gestational age, zygosity and chorionicity, parental educational level, maternal smoking during pregnancy, and maternal age. In addition, at birth, we adjusted for birth year and, in models including telomere length at adulthood and telomere ranking, we included adult age, smoking in adulthood, and gamma-glutamyl transferase in fasting blood in adulthood (as an index for alcohol consumption). To account for the phenomenon of regression towards the mean, we included telomere length at birth in longitudinal analysis (ranking) and we tested the interaction between baseline telomere length and our exposure variable (residential 
distance to major road). The interaction term between baseline telomere length (birth) and early-life traffic exposure was not significant $(P=0.26)$ and therefore not kept in the model.

We ran two sensitivity analyses, namely (1) with additional adjustment for 24-h urinary cortisol in adulthood and (2) combining both the early-life and adulthood residential distance to a major road.

\section{Results}

\section{Characteristics of the study population}

Table 1 summarizes the characteristics of the study population. The study population includes 117 mothers; 57.3\% $(n=134)$ of the participants included both twins from each twin pair, whereas the remaining $42.7 \%(n=50)$ only had one participating twin from each twin pair. Information on telomere length in buccal cells and placental tissue was available for 184 twins, of which 121 (65.8\%) were monozygotic and 63 (34.2\%) dizygotic. At the time of

Table 1 Study population characteristics

\begin{tabular}{|c|c|}
\hline Maternal & $n=117$ \\
\hline Maternal age, years & $26.7 \pm 4.1$ \\
\hline Smoking during pregnancy, $\mathrm{n}$ & $13(11.1)$ \\
\hline \multicolumn{2}{|c|}{ Socioeconomic status: maternal education } \\
\hline Low & $46(39.3)$ \\
\hline Middle & $28(23.9)$ \\
\hline High & $43(36.8)$ \\
\hline Birth & $n=184$ \\
\hline Gestational age, weeks & $37.2 \pm 2.5$ \\
\hline Neonate birth weight, $g$ & $2589 \pm 506$ \\
\hline Twin birth year & $1976 \pm 3.2$ \\
\hline \multicolumn{2}{|l|}{ Zygosity - Chorionicity } \\
\hline Dizygotic - Dichorionic & $63(34.2)$ \\
\hline Monozygotic - Dichorionic & $55(29.9)$ \\
\hline Monozygotic - Monochorionic & $66(35.9)$ \\
\hline Adulthood & $n=184$ \\
\hline Age, years & $22.6 \pm 3.1$ \\
\hline \multicolumn{2}{|l|}{ Sex } \\
\hline Male & $93(50.5)$ \\
\hline Female & $91(49.5)$ \\
\hline Body mass index, $\mathrm{kg} / \mathrm{m}^{2}$ & $21.5 \pm 2.7$ \\
\hline Smokers, $\mathrm{n}$ & $64(34.8)$ \\
\hline Gamma-glutamyl transferase, U/L & $17.8 \pm 11.1$ \\
\hline Total cortisol $(\mu \mathrm{g} / \mathrm{dL})$ & $97.1 \pm 41.4$ \\
\hline \multicolumn{2}{|l|}{ Complete-pair in final study } \\
\hline One twin & $50(42.7)$ \\
\hline Both twins & $134(57.3)$ \\
\hline Moved since birth & $122(66.3)$ \\
\hline
\end{tabular}

Data presented are means \pm standard deviation or number (percentage) collection of buccal swabs the twins had a mean (SD) age of 22.6 (3.1) years. The median distance to the nearest major road was $352 \mathrm{~m}$ (interquartile range (IQR), 166$1218 \mathrm{~m})$ at the residential address at birth and $392 \mathrm{~m}$ (IQR, 128-822 $\mathrm{m}$ ) at the residential address at adult age.

\section{Association between telomere length in placental tissue and buccal swabs}

Telomere length in buccal cells in adulthood was positively associated with placental telomere length $(\mathrm{r}=0.31$, $P<0.0001)$ (Fig. 2). The mean T/S (SD) was $0.90(0.78)$ for placental tissue and $1.05(0.29)$ in adult buccal cells.

\section{Determinants of telomere tracking from birth to adulthood}

Participants with a relative long telomere length at birth exhibited a stronger downward (accelerated shortening) shift in ranking compared to participants with short placental telomeres $(-24.6$; 95\% confidence interval (CI) -29.4 to $-19.9 ; P<0.0001)$. In addition, a downward shift in telomere ranking was also associated with higher adult age $(P=0.03)$, higher alcohol intake $(P=0.02)$, and higher parental education $(P=0.04)$. An upward shift (decelerate shortening) in telomere ranking between birth and adulthood was observed in women compared with men $(P=0.04)$. Table 2 shows these results.

Table 2 Predictors of telomere length ranking between birth and young adulthood

\begin{tabular}{|c|c|c|c|}
\hline \multirow[b]{2}{*}{ Predictors } & \multicolumn{3}{|c|}{ Multi variable model } \\
\hline & $\begin{array}{l}\text { Change in } \\
\text { ranking }\end{array}$ & $95 \% \mathrm{Cl}$ & $P$ value \\
\hline \multicolumn{4}{|l|}{ Early-life covariates } \\
\hline $\begin{array}{l}\text { Placental telomere } \\
\text { length, + IQR }\end{array}$ & -24.6 & -29.4 to -19.9 & $<0.0001$ \\
\hline Newborn girls & 9.9 & 0.8 to 19.0 & 0.04 \\
\hline Birth weight, +IQR & 1.3 & -6.4 to 9.0 & 0.76 \\
\hline Gestational age, +IQR & -3.4 & -10.2 to 3.4 & 0.34 \\
\hline Parental education level & -5.4 & -10.5 to -0.4 & 0.04 \\
\hline Smoking during pregnancy & -8.3 & -23.0 to 6.4 & 0.27 \\
\hline $\begin{array}{l}\text { Residential distance to } \\
\text { major road early-life, } \\
\text { 2-fold change }\end{array}$ & 8.7 & 1.2 to 16.1 & 0.03 \\
\hline \multicolumn{4}{|l|}{ Adult covariates } \\
\hline Age, +1 year & -1.7 & -3.2 to -0.3 & 0.03 \\
\hline Smoking & -8.3 & -17.1 to 0.5 & 0.07 \\
\hline $\begin{array}{l}\text { Gamma-glutamyl } \\
\text { transferase, +IQR }\end{array}$ & -4.0 & -7.4 to -0.7 & 0.02 \\
\hline
\end{tabular}

To examine telomere tracking over life we ranked telomere length at birth (based on placental telomere) and at adult life (based on buccal cell telomere length). We studied the difference in ranking, a negative difference in ranking between birth and young adulthood means a decline in ranking to 100 faster than the average of the population

$\mathrm{Cl}$ confidence interval, IQR interquartile range 


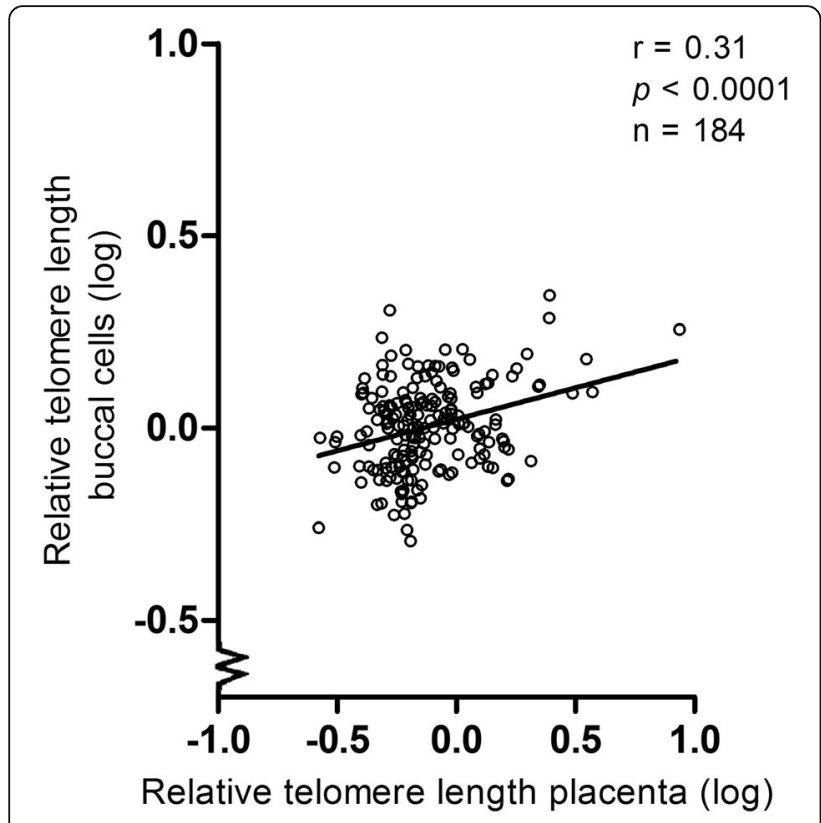

Fig. 2 Relative telomere length in buccal cells in young adulthood in association with relative placental telomere length at birth

\section{Birth and adulthood telomere length and residential traffic indicators}

Twins living farther away from a major road at the birth address had both longer placental telomere at birth and longer buccal telomere length at adulthood. In twins who moved during life $(\mathrm{n}=122)$, the corresponding estimates expressed for a doubling in distance between residence and major road showed $3.6 \%$ longer placental telomeres at birth (95\% CI 0.3 to $7.0 ; P=0.04)$ and a $2.5 \%$ longer buccal telomere length in adulthood (95\%
CI 0.6 to $4.5 ; P=0.01)$. This association was observed before (Fig. 3a) and after adjustments for covariates (Fig. 4a). After additional adjustment for 24-h urinary cortisol (adulthood), the association between buccal telomere length and traffic exposure remained significant (Additional file 1: Figure S1A).

\section{Telomere tracking from birth to adulthood and residential traffic}

We noted that traffic exposure in early life is significantly associated with telomere length in adulthood and with telomere ranking in twins who moved during life (living at a different address than their birth address at the time of measurement, $\mathrm{n}=122$ ). Lower traffic exposure at birth showed a upward shift (decelerated shortening) in telomere ranking between birth and young adulthood (Fig. 3b). A doubling in distance in early-life residential distance to a major road was significantly associated with an upward shift in ranking $(2.9 ; 95 \% \mathrm{CI}$ 0.29 to $5.5 ; P=0.04$ ) (Fig. $4 \mathrm{~b}$ ). We observed no significant association of residential distance to a major road in young adulthood or in persons living at the same address their whole life (non-movers) with adult telomere length and telomere ranking. Finally, we ran a sensitivity analysis in movers to estimate the independence of early-life exposure from adulthood exposure and therefore combined both early-life and adulthood residential proximity to a major road in the same model along with the aforementioned covariates. This was confirmatory, showing that a doubling in distance in early-life residential distance to a major road was significantly associated with an upward shift in ranking (2.6; 95\% CI 0.5 to $4.8 ; P=0.02$ ).
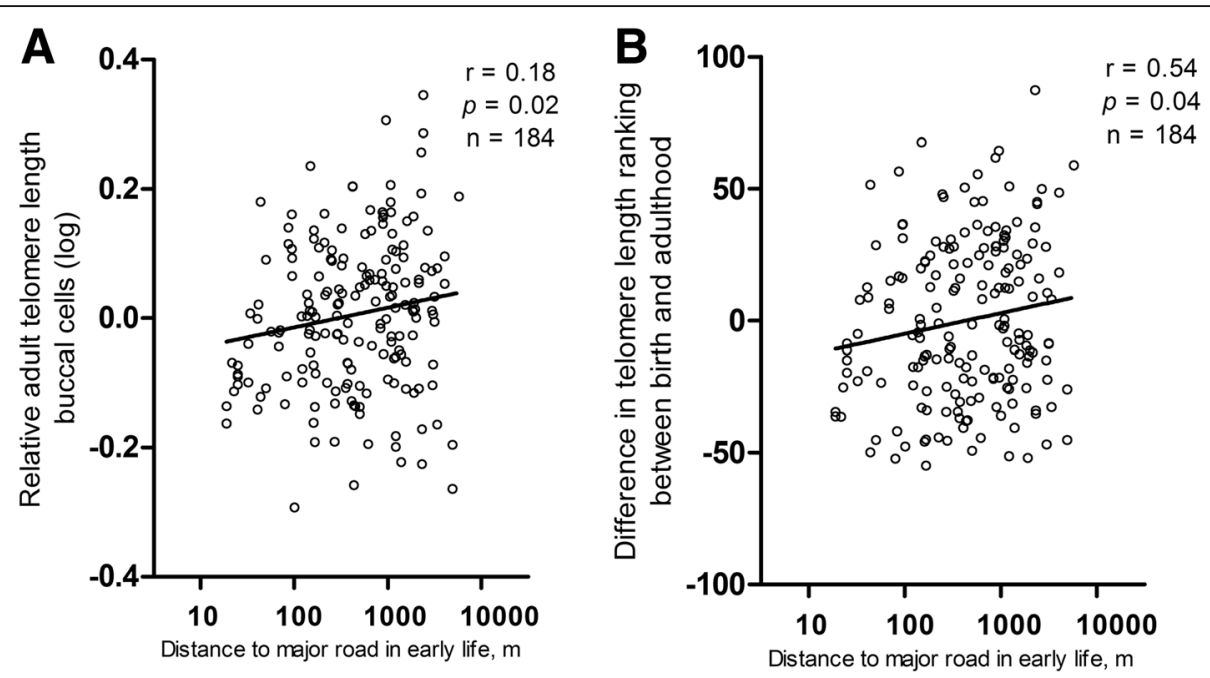

Fig. 3 a Relative telomere length in buccal cells in adulthood (log) in association with distance to major road at the residential address at birth. $\mathbf{b}$ Difference in telomere length ranking between birth and adulthood adjusted for telomere length in placental tissue is associated with distance to major road at the residential address at birth 

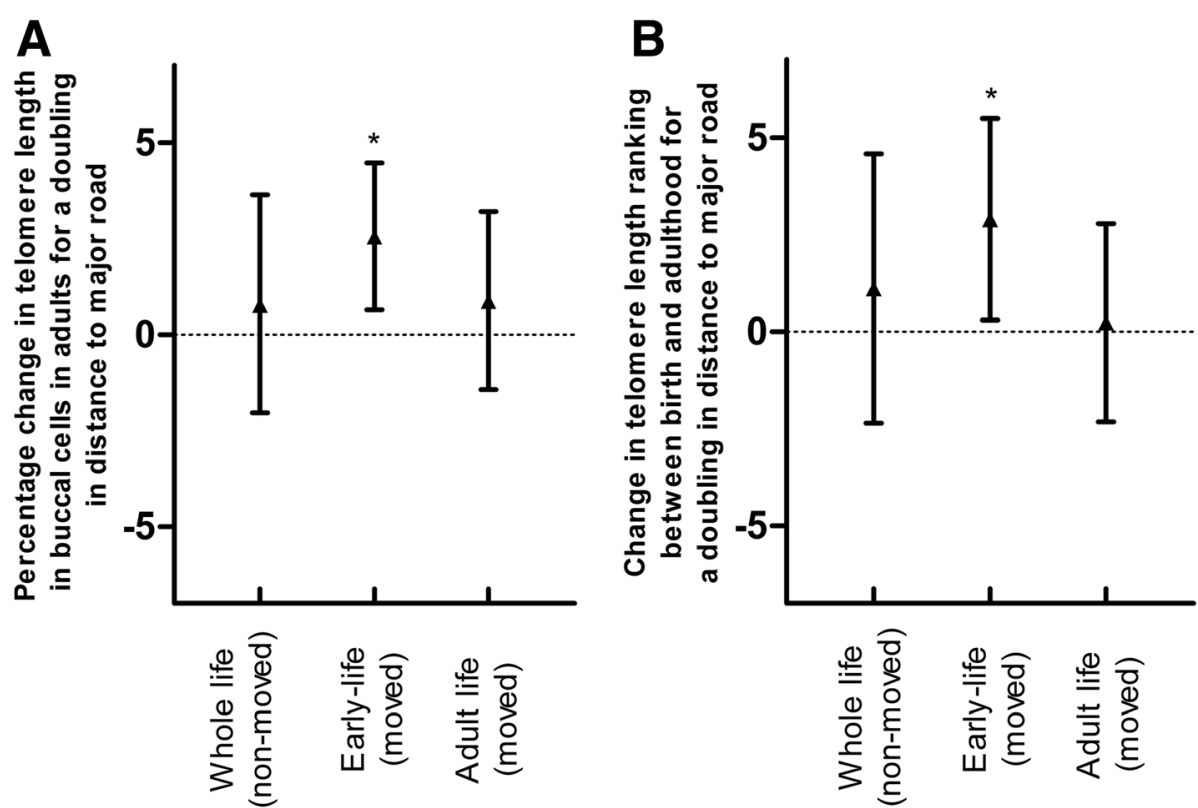

Fig. 4 Distance to the nearest major road in association with (a) telomere length in buccal cells and (b) change in telomere length ranking between birth and adulthood. Adjusted for newborn sex, birth weight, gestational age, zygosity and chorionicity, parental educational level, maternal smoking during pregnancy, maternal age, adult age, smoking in adulthood, gamma-glutamyl transferase in fasting blood in adulthood (as an index for alcohol consumption), and telomere length in placental tissue at birth. Vertical lines denote 95\% confidence intervals. *Indicates a significant $(P<0.05)$ change in buccal telomere length in adulthood or a change in telomere ranking. Effect size for a two-fold increase in distance from residence to major road in early/adult life (based on a model with log distance) in movers $(n=122)$ or in distance from residence to major road during whole life in non-movers $(n=62)$

\section{Discussion}

Persons of the same age vary greatly with regards to telomere length, and this variation is present from early life [35]. Here, we studied telomere tracking from birth to young adulthood (18-30 years). The combination of both telomere measurements at birth and in adulthood is unique and has not been previously reported. Telomere length at birth (placental tissue) and in adulthood (buccal cells) were positively correlated. Independent of telomere length at birth, a lower buccal telomere length was observed in adults who had higher residential exposure to traffic early in life. In addition, the rank changes from birth to adulthood showed a stronger downward shift in telomere ranking over life in those that had higher residential traffic exposure at the birth address, while traffic exposure at the residential address at adult age was not associated with telomere length. Our study has important implications; based on telomere measures at birth and in adulthood, we found that the inverse association between prenatal traffic-related exposure and telomere length is not only perceived at birth but lasts over the life course.

We show a positive association between placental telomere length at birth and buccal telomere length in adulthood, which emphasizes the importance of understanding factors that determine early-life telomere length. An experimental study in zebra finches showed that telomere length early in life is a strong predictor of lifespan [36].

Our findings between telomere length and traffic exposure are in line with recent reported associations between adult traffic exposure and telomere length in adulthood. In Belgium, residential annual average exposure to particles less than $2.5 \mu \mathrm{m}$ in diameter $\left(\mathrm{PM}_{2.5}\right)$ was associated with shorter telomere length, lower mtDNA content, and reduced SIRT1 expression in peripheral blood leukocytes of the elderly [21]. In a cohort of 165 never-smoker elderly men, an IQR increase in annual black carbon exposure $\left(0.25 \mu \mathrm{g} / \mathrm{m}^{3}\right)$, a marker of trafficrelated air pollution, was associated with an $8 \%$ decrease in leukocyte telomere length ( $95 \%$ CI $-13 \%$ to $-2 \%$ ) [19]. Further, a study comparing traffic officers exposed to high levels of traffic pollutants with office workers showed shorter telomere length in traffic officers [20].

We assume that the underlying mechanism between traffic exposure and telomere length is oxidative stress and inflammation. Road traffic contributes largely to particulate matter pollution. Phagocytosis of these particles by alveolar macrophages in the lungs can result in oxidative stress and inflammation [37, 38]. However, traffic-related ultrafine particles can even translocate into the blood circulation and result in local effects [39]. The blood circulation of the mother can transport these 
particles to the placenta and particles with a diameter of less than $240 \mathrm{~nm}$ are able to cross the placental barrier, resulting in direct effects [40]. However, even larger particles, which are not able cross the barrier, can cause oxidative stress in the placenta and indirectly affect the fetus. Recently, it was shown that maternal exposure to particulate air pollution during pregnancy was associated with higher placental 3-nitrotyrosine levels, a biomarker of oxidative stress [41]. Telomeres are highly sensitive to oxidative stress due to their high guanine content and the inefficient repair system of single-strand breaks [42].

Besides oxidative stress, an underlying link between traffic exposure and telomere length may be maternal perceived stress. Previous studies [43-45] highlight the importance of stress when studying telomere length. It was found that women with the highest levels of perceived stress have, on average, shorter telomeres by the equivalent of at least one decade of additional aging compared to low stress women [43]. Further research showed that maternal psychological stress during pregnancy is associated with newborn telomere length [44] and that prenatal exposure to stress was significantly associated with shorter telomere length in young adulthood [45]. The association between buccal telomere length and traffic exposure remained significant after additional adjustment for cortisol. However, higher traffic-related exposure might also induce higher prenatal stress. A limitation of this study is that cortisol was not measured at birth.

Our findings suggest an inverse association between telomere attrition and initial telomere length, wherein attrition rate is more pronounced in newborns with longer placental telomeres at baseline. These results are consistent with previous reports of an inverse association between telomere attrition rate and initial telomere length in blood samples [12, 46, 47]. Three reasons for the inverse association between telomere attrition and initial telomere length have been proposed [12, 46, 47]. First, longer telomeres are more susceptible to oxidative stress due the sensitivity of the telomeric $\mathrm{G}$ triplet to oxidative damage [12]. Second, telomerase acts preferentially on short telomeres as a protection mechanism [47]. Third, it might be possible that the correlation between telomere attrition and baseline telomere length is largely, but not completely, explained by the statistical phenomena of regression to the mean [48]. In our analysis, we accounted for the phenomenon of regression towards the mean by adjusting for telomere length at baseline.

The present study should be interpreted in the context of its limitations. First, telomere length at birth and in young adulthood have been measured in different tissues and with slightly different methods. The rates of telomere shortening are similar in somatic tissues [49]. However, to avoid methodological issues due to difference in tissue and methods, we rather focused on the change in telomere ranking over this period. Second, telomere length in adulthood was not measured in blood but in buccal cells. Despite the absolute difference in telomere length between tissues, strong intraindividual correlations in telomere length have been observed between blood and buccal cells [50]. However, these results were not confirmed by other related studies [51]. In adults [49], and even at birth [52, 53], a high synchrony in telomere length between tissues is present and age-dependent telomere attrition during adulthood is very similar across different somatic tissues. A disadvantage of buccal cells is that poor oral hygiene or infection during sampling can alter oral cell composition [54]. Nevertheless, buccal cell telomeres may be more inert and less influenced by regulatory factors than white blood cells due to the different cell populations in blood [54]. Third, we do not have high resolution residential air pollution data of the pregnancy period. Indeed, the samples of this twin study were collected from 1969 to 1982 and no high resolution ambient air pollution data of this period are available. A limitation inherent to the use of a proxy marker for traffic exposure, i.e., residential distance to a major road, is that it does not take into account individual differences in the time spent at home and in other environments. However, the proxy of residential distance to a major road is currently still used in environmental epidemiology [55-57] and we recently showed that it correlates with the black carbon load in children's urine [58]. Fourth, residential distance to a major road at birth and in adulthood were correlated $(\mathrm{r}=0.32 ; P<0.001)$. Therefore, to detangle between early and late exposure we cannot completely rule out residual confounding. Nevertheless, a sensitivity analysis, in which both early- and later-life exposure were combined in the same model, confirms the stronger impact of early-life exposure.

\section{Conclusions}

To our knowledge, this is the first longitudinal study measuring telomere length at birth and in adulthood. We showed a correlation between telomere length in placental tissue and in buccal cells in young adulthood. In addition, our results emphasize the importance of the early-life environment on adult telomere length. We noted that traffic-related exposure in early life is not only associated with shorter telomere length in placental tissue but also shorter telomere length in young adulthood. As telomere length is a proposed measure of biological aging, these results suggest that environmental exposure in early life may have implications for health outcomes later in life and that age-related diseases may have their origin in the early-life environment. 


\section{Additional file}

Additional file 1: Figure S1. Distance to the nearest major road in association with (A) telomere length in buccal cells and (B) change in telomere length ranking between birth and adulthood. Adjusted for newborn sex, birth weight, gestational age, zygosity and chorionicity, parental education level, maternal smoking during pregnancy, maternal age, adult age, smoking in adulthood, gamma-glutamyl transferase in fasting blood in adulthood (as an index for alcohol consumption), 24-h urinary total cortisol, and telomere length in placental tissue at birth. Vertical lines denote $95 \%$ confidence intervals. ${ }^{*}$ ndicates significant $(P<0.05)$ change in buccal telomere length in adulthood or change in telomere ranking. Effect size for a two-fold increase in distance from residence to major road in early/ adult life (based on a model with log distance) in movers $(n=109)$ or in distance from residence to major road during whole life in non-movers ( $\mathrm{n}=57)$. (DOCX $196 \mathrm{~kb}$ )

\section{Abbreviations}

$\mathrm{Cl}$ : confidence interval; IQR: interquartile range; SD: standard deviation; T/S ratio: telomere to single copy gene ratio

\section{Acknowledgements}

Not applicable.

\section{Funding}

This investigation is supported by the EU research council "project ENVIRONAGE" (ERC-2012-StG 310890), and the Flemish Scientific Fund (G073315N). Dr. Bijnens holds a fellow-ship from the Marguerite-Marie Delacroix foundation. Since its start, the East Flanders Prospective Twin Survey has been partly supported by grants from the Fund of Scientific Research Flanders and Twins, a non-profit Association for Scientific Research in Multiple Births (Belgium). The funders had no role in the design of the study and interpretation of the results.

\section{Availability of data and materials}

The datasets used and/or analyzed during the current study are available from the corresponding author on reasonable request.

\section{Authors' contributions}

RV, CD, TSN, MPZ, MG and EMB designed the study. CD, ET, MG and EMB performed data collection. DSM and MP optimized the telomere length protocol. GJH performed the placental telomere length measurements. EMB performed the telomere length measurements in buccal cells. TSN, MPZ and EMB analyzed the data. EMB and TSN wrote the first draft of the manuscript. All authors critically revised and approved the final version of the manuscript.

\section{Ethics approval and consent to participate}

Written informed consent was obtained from all participants, and ethical approval was given by the Ethics Committee of the Faculty of Medicine of the Katholieke Universiteit Leuven (reference no. B32220096237).

\section{Consent for publication}

Not applicable.

\section{Competing interests}

The authors declare that they have no competing interests.

\section{Publisher's Note}

Springer Nature remains neutral with regard to jurisdictional claims in published maps and institutional affiliations.

\section{Author details}

${ }^{1}$ Centre for Environmental Sciences, Hasselt University, Agoralaan Building D, 3590 Diepenbeek, Belgium. ${ }^{2}$ Department of Complex Genetics, NUTRIM School of Nutrition and Translational Research in Metabolism, Maastricht University Medical Centre, Maastricht, The Netherlands. ${ }^{3}$ CAPHRI School for Public Health and Primary Care, Maastricht University, Maastricht, The Netherlands. ${ }^{4}$ Department of Obstetrics and Gynecology, Ghent University
Hospitals, Ghent, Belgium. ${ }^{5}$ Centre of Human Genetics, University Hospitals Leuven, Leuven, Belgium. ${ }^{6}$ Department of Toxicology, NUTRIM School of Nutrition and Translational Research in Metabolism, Maastricht University Medical Centre, Maastricht, The Netherlands. ${ }^{7}$ Department of Neurology, Ghent University Hospitals, Ghent, Belgium. ${ }^{8}$ Department of Public Health, Leuven University (KU Leuven), Leuven, Belgium.

\section{Received: 24 March 2017 Accepted: 23 October 2017}

Published online: 21 November 2017

\section{References}

1. Blackburn EH. Switching and signaling at the telomere. Cell. 2001;106(6):661-73.

2. Harley $C B$, Futcher $A B$, Greider $C W$. Telomeres shorten during ageing of human fibroblasts. Nature. 1990;345(6274):458-60.

3. Collins K, Mitchell JR. Telomerase in the human organism. Oncogene. 2002;21(4):564-79.

4. Haycock PC, Heydon E, Kaptoge S, Butterworth AS, Thompson A, Willeit P. Leucocyte telomere length and risk of cardiovascular disease: systematic review and meta-analysis. BMJ. 2014;349(g4227):g4227.

5. Zhao J, Miao K, Wang H, Ding H, Wang DW. Association between telomere length and type 2 diabetes mellitus: a meta-analysis. PLoS One. 2013;8(11):e79993.

6. Wentzensen IM, Mirabello L, Pfeiffer RM, Savage SA. The association of telomere length and cancer: a meta-analysis. Cancer Epidemiol Biomarkers Prev. 2011;20(6):1238-50.

7. Ma H, Zhou Z, Wei S, Liu Z, Pooley KA, Dunning AM, Svenson U, Roos G, Hosgood 3rd HD, Shen M, et al. Shortened telomere length is associated with increased risk of cancer: a meta-analysis. PLoS One. 2011;6(6):e20466.

8. Kimura M, Hjelmborg JV, Gardner JP, Bathum L, Brimacombe M, Lu X, Christiansen L, Vaupel JW, Aviv A, Christensen K. Telomere length and mortality: a study of leukocytes in elderly Danish twins. Am J Epidemiol. 2008;167(7):799-806.

9. Bakaysa SL, Mucci LA, Slagboom PE, Boomsma DI, McClearn GE, Johansson $B$, Pedersen NL. Telomere length predicts survival independent of genetic influences. Aging Cell. 2007;6(6):769-74.

10. Chen W, Kimura M, Kim S, Cao X, Srinivasan SR, Berenson GS, Kark JD, Aviv A. Longitudinal versus cross-sectional evaluations of leukocyte telomere length dynamics: age-dependent telomere shortening is the rule. J Gerontol A Biol Sci Med Sci. 2011;66(3):312-9.

11. Martens DS, Nawrot TS. Air pollution stress and the aging phenotype: the telomere connection. Curr Envrion Health Rep. 2016;3(3):258-69.

12. Aviv A, Chen W, Gardner JP, Kimura M, Brimacombe M, Cao X, Srinivasan SR, Berenson GS. Leukocyte telomere dynamics: longitudinal findings among young adults in the Bogalusa Heart Study. Am J Epidemiol. 2009;169(3):323-9.

13. Farzaneh-Far R, Lin J, Epel E, Lapham K, Blackburn E, Whooley MA. Telomere length trajectory and its determinants in persons with coronary artery disease: longitudinal findings from the heart and soul study. PLoS One. 2010;5(1):e8612

14. Gardner JP, Li S, Srinivasan SR, Chen W, Kimura M, Lu X, Berenson GS, Aviv A. Rise in insulin resistance is associated with escalated telomere attrition. Circulation. 2005;111(17):2171-7.

15. Frenck Jr RW, Blackburn EH, Shannon KM. The rate of telomere sequence loss in human leukocytes varies with age. Proc Natl Acad Sci U S A. 1998;95(10):5607-10.

16. Rufer N, Brummendorf TH, Kolvraa S, Bischoff C, Christensen K, Wadsworth L, Schulzer M, Lansdorp PM. Telomere fluorescence measurements in granulocytes and $T$ lymphocyte subsets point to a high turnover of hematopoietic stem cells and memory T cells in early childhood. J Exp Med. 1999;190(2):157-67.

17. Benetos A, Kark JD, Susser E, Kimura M, Sinnreich R, Chen W, Steenstrup T, Christensen K, Herbig U, von Bornemann HJ, et al. Tracking and fixed ranking of leukocyte telomere length across the adult life course. Aging Cell. 2013:12(4):615-21.

18. Factor-Litvak $P$, Susser $E$. The importance of early life studies of telomere attrition. Paediatr Perinat Epidemiol. 2015;29(2):144-5.

19. McCracken J, Baccarelli A, Hoxha M, Dioni L, Melly S, Coull B, Suh H, Vokonas P, Schwartz J. Annual ambient black carbon associated with shorter telomeres in elderly men: Veterans Affairs Normative Aging Study. Environ Health Perspect. 2010;118(11):1564-70.

20. Hoxha M, Dioni L, Bonzini M, Pesatori AC, Fustinoni S, Cavallo D, Carugno M, Albetti B, Marinelli B, Schwartz J, et al. Association between leukocyte 
telomere shortening and exposure to traffic pollution: a cross-sectional study on traffic officers and indoor office workers. Environ Health. 2009;8:41.

21. Pieters $N$, Janssen BG, Dewitte $H$, Cox B, Cuypers A, Lefebvre W, Smeets $K$, Vanpoucke C, Plusquin M, Nawrot TS. Biomolecular markers within the core axis of aging and particulate air pollution exposure in the elderly: a crosssectional study. Environ Health Perspect. 2015;124(7):943-50.

22. Bijnens EM, Derom C, Gielen M, Winckelmans E, Fierens F, Vlietinck R, Zeegers MP, Nawrot TS. Small for gestational age and exposure to particulate air pollution in the early-life environment of twins. Environ Res. 2016;148:39-45.

23. Bijnens E, Zeegers MP, Gielen M, Kicinski M, Hageman GJ, Pachen D, Derom C, Vlietinck R, Nawrot TS. Lower placental telomere length may be attributed to maternal residential traffic exposure; a twin study. Environ Int 2015;79:1-7.

24. Derom C, Thiery E, Peeters H, Vlietinck R, Defoort P, Frijns JP. The East Flanders Prospective Twin Survey (EFPTS): an actual perception. Twin Res Hum Genet. 2013;16(1):58-63.

25. Loos RJ, Beunen G, Fagard R, Derom C, Vlietinck R. The influence of zygosity and chorion type on fat distribution in young adult twins consequences for twin studies. Twin Res. 2001;4(5):356-64.

26. Gielen M, Hageman G, Pachen D, Derom C, Vlietinck R, Zeegers MP. Placental telomere length decreases with gestational age and is influenced by parity: a study of third trimester live-born twins. Placenta. 2014;35(10):791-6.

27. Cawthon RM. Telomere length measurement by a novel monochrome multiplex quantitative PCR method. Nucleic Acids Res. 2009;37(3):e21.

28. Hellemans J, Mortier G, De Paepe A, Speleman F, Vandesompele J. qBase relative quantification framework and software for management and automated analysis of real-time quantitative PCR data. Genome Biol. 2007:8(2):R19.

29. Vlietinck R. Determination of the Zygosity of Twins, PhD Thesis. Leuven: Catholic University of Leuven; 1986.

30. Whitfield JB. Gamma Glutamyl Transferase. Crit Rev in Clin Lab Sci. 2008; 38(4):263-355.

31. Lee DY, Kim E, Choi MH. Technical and clinical aspects of cortisol as a biochemical marker of chronic stress. BMB Rep. 2015;48(4):209-16.

32. Nawrot TS, Vos R, Jacobs L, Verleden SE, Wauters S, Mertens V, Dooms C, Hoet PH, Van Raemdonck DE, Faes C, et al. The impact of traffic air pollution on bronchiolitis obliterans syndrome and mortality after lung transplantation. Thorax. 2011;66(9):748-54.

33. Zhu Y, Hinds WC, Kim S, Sioutas C. Concentration and size distribution of ultrafine particles near a major highway. J Air Waste Manag Assoc. 2002;52(9):1032-42.

34. Bijnens EM, Nawrot TS, Loos RJ, Gielen M, Vlietinck R, Derom C, Zeegers MP. Blood pressure in young adulthood and residential greenness in the earlylife environment of twins. Environ Health. 2017;16(1):53.

35. Martens DS, Plusquin M, Gyselaers W, De Vivo I, Nawrot TS. Maternal prepregnancy body mass index and newborn telomere length. BMC Med. 2016;14(1):148.

36. Heidinger BJ, Blount JD, Boner W, Griffiths K, Metcalfe NB, Monaghan P. Telomere length in early life predicts lifespan. Proc Natl Acad Sci U S A. 2012;109(5):1743-8.

37. Iwai K, Adachi S, Takahashi M, Moller L, Udagawa T, Mizuno S, Sugawara I. Early oxidative DNA damages and late development of lung cancer in diesel exhaust-exposed rats. Environ Res. 2000:84(3):255-64.

38. Li YJ, Takizawa H, Azuma A, Kohyama T, Yamauchi Y, Takahashi S, Yamamoto M, Kawada T, Kudoh S, Sugawara I. Disruption of Nrf2 enhances susceptibility to airway inflammatory responses induced by low-dose diesel exhaust particles in mice. J Clin Immunol. 2008;128(3):366-73.

39. Nemmar A, Hoet PH, Vanquickenborne B, Dinsdale D, Thomeer M, Hoylaerts MF, Vanbilloen H, Mortelmans L, Nemery B. Passage of inhaled particles into the blood circulation in humans. Circulation. 2002:105(4):411-4.

40. Wick P, Malek A, Manser P, Meili D, Maeder-Althaus X, Diener L, Diener PA, Zisch A, Krug HF, von MU. Barrier capacity of human placenta for nanosized materials. Environ Health Perspect. 2010;118(3):432-6.

41. Saenen ND, Vrijens K, Janssen BG, Madhloum N, Peusens M, Gyselaers W, Vanpoucke C, Lefebvre W, Roels HA, Nawrot TS. Placental nitrosative stress and exposure to ambient air pollution during gestation: a population study. Am J Epidemiol. 2016;184(6):442-9.

42. von Zglinicki T. Role of oxidative stress in telomere length regulation and replicative senescence. Ann N Y Acad Sci. 2000;908:99-110.
43. Epel ES, Blackburn EH, Lin J, Dhabhar FS, Adler NE, Morrow JD, Cawthon RM. Accelerated telomere shortening in response to life stress. Proc Natl Acad Sci U S A. 2004;101(49):17312-5.

44. Entringer S, Epel ES, Lin J, Buss C, Shahbaba B, Blackburn EH, Simhan HN, Wadhwa PD. Maternal psychosocial stress during pregnancy is associated with newborn leukocyte telomere length. Am J Obstet Gynecol. 2013. 208(2):134 e131-137.

45. Entringer S, Epel ES, Kumsta R, Lin J, Hellhammer DH, Blackburn EH, Wust S, Wadhwa PD. Stress exposure in intrauterine life is associated with shorter telomere length in young adulthood. Proc Natl Acad Sci U S A. 2011; 108(33):E513-8.

46. Weischer M, Bojesen SE, Nordestgaard BG. Telomere shortening unrelated to smoking, body weight, physical activity, and alcohol intake: 4,576 general population individuals with repeat measurements 10 years apart. PLoS Genet. 2014:10(3):e1004191.

47. Nordfjall K, Svenson U, Norrback KF, Adolfsson R, Lenner P, Roos G. The individual blood cell telomere attrition rate is telomere length dependent. PLoS Genet. 2009;5(2):e1000375.

48. Verhulst S, Aviv A, Benetos A, Berenson GS, Kark JD. Do leukocyte telomere length dynamics depend on baseline telomere length? An analysis that corrects for 'regression to the mean'. Eur J Epidemiol. 2013;28(11):859-66.

49. Daniali L, Benetos A, Susser E, Kark JD, Labat C, Kimura M, Desai K, Granick M, Aviv A. Telomeres shorten at equivalent rates in somatic tissues of adults. Nat Commun. 2013;4:1597.

50. Gadalla SM, Cawthon R, Giri N, Alter BP, Savage SA. Telomere length in blood, buccal cells, and fibroblasts from patients with inherited bone marrow failure syndromes. Aging. 2010;2(11):867-74.

51. Thomas $P, O^{\prime}$ Callaghan NJ, Fenech M. Telomere length in white blood cells, buccal cells and brain tissue and its variation with ageing and Alzheimer's disease. Mech Ageing Dev. 2008;129(4):183-90.

52. Youngren K, Jeanclos E, Aviv H, Kimura M, Stock J, Hanna M, Skurnick J, Bardeguez A, Aviv A. Synchrony in telomere length of the human fetus. Hum Genet. 1998:102(6):640-3.

53. Okuda K, Bardeguez A, Gardner JP, Rodriguez P, Ganesh V, Kimura M, Skurnick J, Awad G, Aviv A. Telomere length in the newborn. Pediatr Res. 2002;52(3):377-81

54. Shalev I. Early life stress and telomere length: investigating the connection and possible mechanisms: a critical survey of the evidence base, research methodology and basic biology. Bioessays. 2012;34(11):943-52.

55. Nawrot TS, Perez L, Kunzli N, Munters E, Nemery B. Public health importance of triggers of myocardial infarction: a comparative risk assessment. Lancet. 2011:377(9767):732-40.

56. Dijkema MB, Mallant SF, Gehring U, van den Hurk K, Alssema M, van Strien RT, Fischer PH, Nijpels G, Stehouwer CD, Hoek G, et al. Long-term exposure to traffic-related air pollution and type 2 diabetes prevalence in a crosssectional screening-study in the Netherlands. Environ Health. 2011:10:76.

57. Baccarelli A, Martinelli I, Pegoraro V, Melly S, Grillo P, Zanobetti A, Hou L, Bertazzi PA, Mannucci PM, Schwartz J. Living near major traffic roads and risk of deep vein thrombosis. Circulation. 2009;119(24):3118-24.

58. Saenen ND, Bové $H$, Steuwe C, Roeffaers MBJ, Provost EB, Lefebvre W, Vanpoucke C, Ameloot M, Nawrot TS. Children's urinary environmental carbon load: a novel marker reflecting residential ambient air pollution exposure? Am J Respir Crit Care Med. 2017;196(7):873-81.

\section{Submit your next manuscript to BioMed Central and we will help you at every step:}

- We accept pre-submission inquiries

- Our selector tool helps you to find the most relevant journal

- We provide round the clock customer support

- Convenient online submission

- Thorough peer review

- Inclusion in PubMed and all major indexing services

- Maximum visibility for your research

Submit your manuscript at www.biomedcentral.com/submit 